\title{
Univariate and Multivariate Analyses of Influencing Factors on Methane Adsorption Capacity of Semianthracite
}

\author{
Shihui Hou, ${ }^{1}$ Xiaoming Wang $\mathbb{D}^{2}{ }^{2}$ Yudong Yuan, ${ }^{3}$ Sidong Pan, ${ }^{2}$ Zheng Dang, ${ }^{2}$ \\ and Chunyong Luo ${ }^{1}$ \\ ${ }^{1}$ Laboratory of Geotechnical Engineering, Jinggangshan University, Ji'an 343000, China \\ ${ }^{2}$ Key Laboratory of Tectonics and Petroleum Resources, China University of Geosciences, Wuhan 430074, China \\ ${ }^{3}$ School of Petroleum Engineering, University of New South Wales, Sydney, NSW 2052, Australia
}

Correspondence should be addressed to Xiaoming Wang; sunwxm@cug.edu.cn

Received 29 November 2019; Accepted 16 December 2020; Published 18 January 2021

Academic Editor: Adrián Bonilla-Petriciolet

Copyright (c) 2021 Shihui Hou et al. This is an open access article distributed under the Creative Commons Attribution License, which permits unrestricted use, distribution, and reproduction in any medium, provided the original work is properly cited.

\begin{abstract}
Methane adsorption isotherm experiments on semianthracite $\left(2.00-2.33 \% R_{o, \max }\right)$ collected from the Xin'an coal mine, Henan Province, China, were conducted to investigate the effects of pore structure, coal quality, coal maceral, and coal rank on methane adsorption capacity with applications of univariate and multivariate analyses. Methane adsorption capacity varies significantly from 12.03 to $28.40 \mathrm{~cm}^{3} / \mathrm{g}$. In univariate analysis, methane adsorption capacity has a strong positive correlation with pore specific surface area, weak positive correlations with pore volume and ash content, and weak negative correlations with moisture content and inertinite content. No correlation is observed between methane adsorption capacity and coal rank. In multivariate analysis, the mathematical model of methane adsorption capacity affected by the combined individual variables is established based on quantification theory I. There are similarities and differences between the two analyses. The similarities are that pore specific surface area has the greatest contribution to methane adsorption capacity, while coal rank has the least contribution. The differences are reflected in two aspects. Firstly, the other influencing factors contribute differently to methane adsorption capacity. Secondly, the positive or negative correlations of some influencing factors present the opposite. The mathematic model synthetically covers the combined effects of the influencing factors, which is more representative in evaluating methane adsorption capacity.
\end{abstract}

\section{Introduction}

Different from conventional gas resources, coalbed methane (CBM) belonging to unconventional gas resources is retained in coal reservoirs in three different forms, including adsorbed gas, free gas, and dissolved gas [1-5]. Among that, the adsorbed state is predominant [4-12]. Understanding of adsorption behavior is extremely important in estimating CBM resource and determining CBM productivity $[9,13]$. More importantly, during underground coal mining, a deeper understanding of methane adsorption capacity is critical to prevent gas-related problems, such as explosive and outburst hazard $[14,15]$. These significances make studies on methane adsorption capacity become one of the most valuable topics [16-18].
Many researches have been performed to investigate factors affecting methane adsorption capacity. In the traditional view, the influencing factors can be divided into two aspects: inherent properties of coal (e.g., coal rank, coal maceral, coal quality, and coal lithotype) and external conditions (e.g., temperature, pressure, burial history, sequence stratigraphy, water occurrence states, and water invasion) $[6-8,13,19-$ 36]. Additionally, other parameters of coal property, including coal deformation [29], macromolecular structure or crystallite structure characteristics of coal $[37,38]$, chemical structure of coal organic matters (e.g., aromatic structure, aliphatic structure, and coal surface functional group) $[6,14,28$, 39], and pore structure characteristics (e.g., pore specific surface area, pore volume, pore size distribution, and fractal characteristics) $[7,28,30,40-44]$, also play important roles 
in methane adsorption capacity. Coal rank is generally considered to be the dominant parameter affecting methane adsorption capacity $[12,45]$. Coal samples used in previous studies, however, show wide range of variation in coal rank $[25,39,46]$, which may mask the effects of other influencing factors. Therefore, for coals with similar rank, more in-depth analyses are essential to understand influencing factors on methane adsorption capacity and to establish a comprehensive mathematical model of methane adsorption capacity. This paper examines the variation of methane adsorption capacity and its influencing factors of the No. $2_{1}$ coal in the Xin'an coal mine, Henan Province, China. The two major objectives are to (1) individually analyze the effects of influencing factors in terms of pore structure, coal quality, coal maceral, and coal rank on methane adsorption capacity and (2) comprehensively establish a mathematic model containing the influencing factors of methane adsorption capacity using multivariate statistical analysis. The research result may serve as an important geological basis for the safety production of the unmined area in the coal mine.

\section{Experiments and Methods}

The study area, the Xin'an coal mine, is located in northwestern Henan Province, China (Figures 1(a) and 1(b)). It spans within a homocline, with NE strike and SE trend. The No. $2{ }_{1}$ coal within the Lower Permian Shanxi Formation is economically minable. The coal underwent extreme tectonic deformation and is classified as tectonically deformed coal. A total of eleven coal samples were collected from six working faces (Figure 1(c)). One of the samples belongs to the working face 12201, two to the working face 13151, five to the working face 14211, one to the working face 14221, and the remaining two to the working faces 15051 and 15061, respectively. The samples were sieved directly and reduced in size to $2 \mathrm{~mm}$ (maximum particle size). Several subsamples of each coal sample were obtained by coning and quartering for proximate analysis, petrographic analysis, low-pressure $\mathrm{N}_{2}$ adsorption analysis, and methane adsorption isotherm experiment.

Proximate analysis was conducted in accordance with ASTM Standards D3173-11 [47], ASTM Standards D3175-11 [48], and ASTM Standards D3174-11 [49]. The polished samples for petrographic analysis were prepared according to the procedure described in Mardon et al. [50]. Maceral analysis (500 point counts) and mean maximum vitrinite reflectance $\left(R_{o \text {,max }}\right)$ measurements were conducted on the same polished sections using a Leitz MPV-3 photometer microscope.

Low-pressure $\mathrm{N}_{2}$ adsorption analysis was performed to obtain pore structure parameters including BrunauerEmmett-Teller $(\mathrm{BET})$ specific surface area $\left(S_{\mathrm{BET}}\right)$ using BET model [51], Barrett-Joyner-Halenda (BJH) pore volume $\left(V_{\mathrm{BJH}}\right)$, and pore size distribution (PSD) according to $\mathrm{BJH}$ model [52]. The samples between $0.18 \mathrm{~mm}$ and $0.25 \mathrm{~mm}$ were used for the experiment with a Micromeritics ASAP 2020 surface area and porosity analyzer. Prior to analysis, the samples were first degassed under vacuum at $105^{\circ} \mathrm{C}$ for $12 \mathrm{~h}$. Both adsorption and desorption isotherms were measured at $77.35 \mathrm{~K}$ for the relative pressure ranging from 0.01 to 0.995 . The adsorption isotherms were used to interpret $S_{\mathrm{BET}}, V_{\mathrm{BJH}}$, and PSDs.

Methane adsorption isotherm experiments on coal samples were conducted on an Isotherm Adsorption/Desorption System ISO-200, following Chinese National Standard GB/T 19560-2008 [53]. The coal samples on the air dry basis were sieved into a particle size fraction of $0.18-0.25 \mathrm{~mm}$ and moisture equilibrated under the controlled relative humidity $(\mathrm{RH})$ condition using saturated salt solutions of $\mathrm{K}_{2} \mathrm{SO}_{4}(97 \% \mathrm{RH})$ for at least four days. The pretreated moisture-equilibrated samples were put into the sample cell of the ISO-200 for the adsorption isotherm experiment. The experimental temperature and equilibrium pressure were $30^{\circ} \mathrm{C}$ and up to $8 \mathrm{MPa}$, respectively. The measured adsorption data were fitted by the Langmuir model [54] to determine the Langmuir constants, i.e., Langmuir volume $\left(V_{L}\right)$ and Langmuir pressure $\left(P_{L}\right)$, and the analytical results were reported on the air dry basis.

\section{Results and Discussion}

3.1. Methane Adsorption Capacity. Coal rank of the samples varies in a relatively small range with $R_{o \text {, max }}$ of $2.00-2.33 \%$ (Table 1). However, methane adsorption capacity (as indicated by $V_{L}$ ) varies widely from $12.03 \mathrm{~cm}^{3} / \mathrm{g}$ to $28.40 \mathrm{~cm}^{3} / \mathrm{g}$ (averaging at $19.66 \mathrm{~cm}^{3} / \mathrm{g}$ ) (Table 1), which suggests a remarkable difference for the coal samples with similar rank. The observation is consistent with Zou et al. [55], where they demonstrated a significant change in methane adsorption capacity of the isorank coals. Methane adsorption capacity greater than $25 \mathrm{~cm}^{3} / \mathrm{g}$ is located in the working face 13151 . Methane adsorption capacity of $20-25 \mathrm{~cm}^{3} / \mathrm{g}$ is concentrated in the working faces 14221, 15051, and 15061. Methane adsorption capacity less than $20 \mathrm{~cm}^{3} / \mathrm{g}$ is distributed in the remaining two working faces 12201 and 14211.

Methane adsorption capacity of different rank coals has been researched in previous publications. For low-rank coal, methane adsorption capacity of coals with $0.34-0.69 \% R_{o \text {, max }}$ varies from $3.33 \mathrm{~cm}^{3} / \mathrm{g}$ to $17.22 \mathrm{~cm}^{3} / \mathrm{g}$ in Moore et al. [56], and that of coals with $0.46-0.73 \% R_{o, \max }$ is between $5.06 \mathrm{~cm}^{3} / \mathrm{g}$ and $13.37 \mathrm{~cm}^{3} / \mathrm{g}$ in Xu et al. [57]. For mediumhigh-rank coal, methane adsorption capacity is from $9.59 \mathrm{~cm}^{3} / \mathrm{g}$ to $21.38 \mathrm{~cm}^{3} / \mathrm{g}$ of coals with $0.68-1.51 \% R_{o, \max }$ in Li et al. [58], from $18.28 \mathrm{~cm}^{3} / \mathrm{g}$ to $23.20 \mathrm{~cm}^{3} / \mathrm{g}$ of coals with $1.23-1.90 \% R_{o, \max }$ in Meng et al. [59], from $12.01 \mathrm{~cm}^{3} / \mathrm{g}$ to $25.36 \mathrm{~cm}^{3} / \mathrm{g}$ of coals with $1.60-2.50 \% R_{o, \max }$ in Yao et al. [34], and from $14.16 \mathrm{~cm}^{3} / \mathrm{g}$ to $43.36 \mathrm{~cm}^{3} / \mathrm{g}$ of coals with $0.96-2.93 \% R_{o, \max }$ in Liu et al. [37]. Compared with the data in the literature mentioned above, the experimental results in our study suggested that the No. $2_{1}$ coal has mediumhigh methane adsorption capacity.

\subsection{Influencing Factors of Methane Adsorption Capacity}

3.2.1. Pore Structure. The low-pressure $\mathrm{N}_{2}$ adsorption and desorption isotherms of the coal samples are presented in Figures 2(a)-2(c). With the similar trend, these isotherms exhibit the feature of physisorption isotherm type IV with hysteresis loop H3 [60, 61]. The occurrence of hysteresis loop 


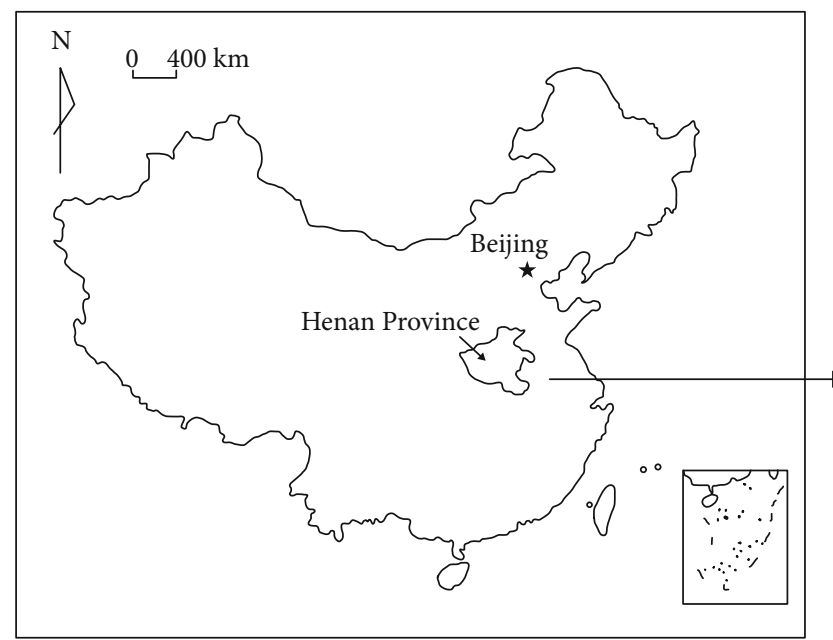

(a)

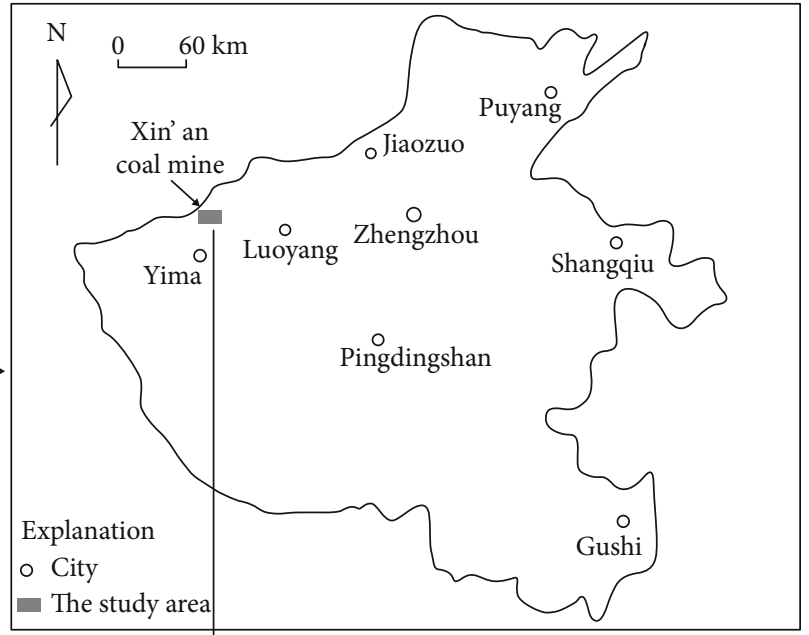

(b)

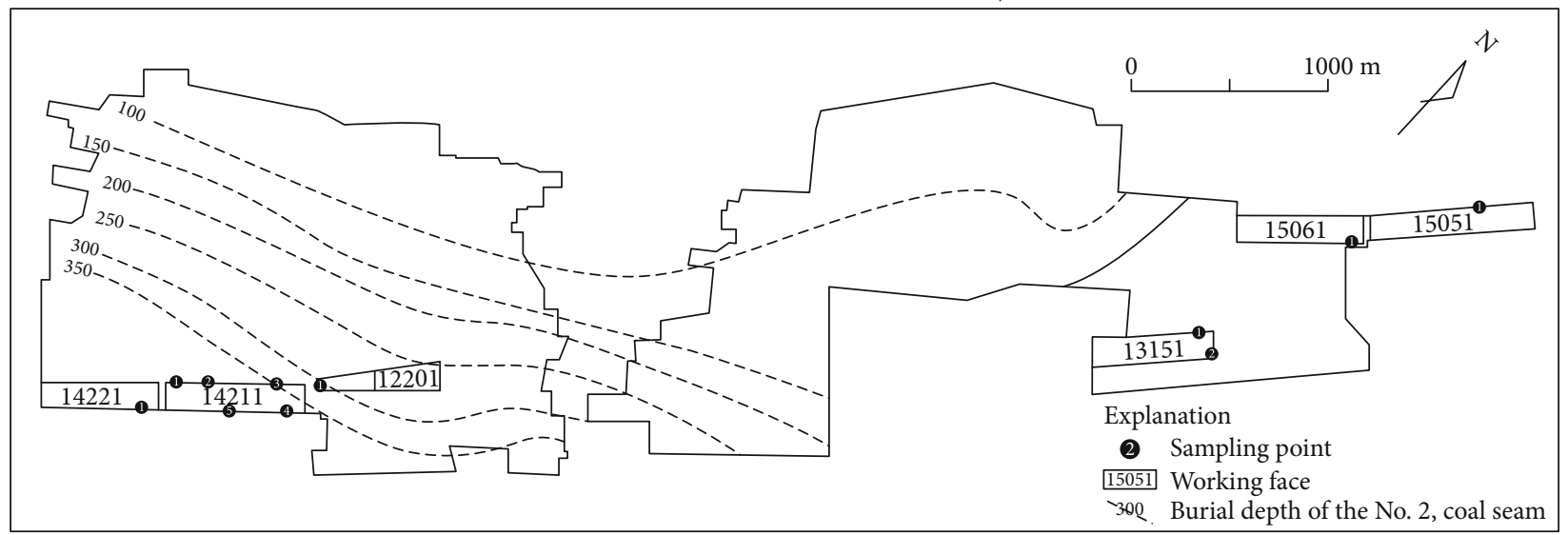

(c)

Figure 1: (a) Location of the Henan Province. (b) Location of the Xin'an coal mine. (c) Map showing sampling points, working faces, and burial depth of the No. $2_{1}$ coal in mining area of the Xin'an coal mine.

TABLE 1: Summarized results of petrographic analysis, proximate analysis, pore structure parameters, and Langmuir constants of the No. $2_{1}$ coal in the Xin'an coal mine.

\begin{tabular}{lcccccccccc}
\hline Coal sample & $\begin{array}{c}R_{o, \max } \\
\%\end{array}$ & $\begin{array}{c}I_{\mathrm{mmf}} \\
\%\end{array}$ & $\begin{array}{c}V_{\mathrm{mmf}} \% \\
12201-1\end{array}$ & $\begin{array}{c}M_{\mathrm{ad}} \\
\%\end{array}$ & $\begin{array}{c}A_{d} \\
\%\end{array}$ & $\begin{array}{c}V_{\text {daf }} \\
\%\end{array}$ & $\begin{array}{c}S_{\mathrm{BET}} \\
\mathrm{m}^{2} / \mathrm{g}\end{array}$ & $\begin{array}{c}V_{\mathrm{BIH}} \\
\mathrm{cm}^{3} / \mathrm{g}\end{array}$ & $\begin{array}{c}V_{L} \\
\mathrm{~cm}^{3} / \mathrm{g}\end{array}$ & $\begin{array}{c}P_{L} \\
\mathrm{MPa}\end{array}$ \\
$13151-1$ & 2.04 & 13.35 & 86.65 & 0.66 & 8.16 & 11.74 & 0.53 & 0.004193 & 15.11 \\
$13151-2$ & 2.17 & 6.33 & 93.67 & 0.56 & 22.54 & 14.31 & 1.64 & 0.006137 & 27.69 \\
$14211-1$ & 2.15 & 7.07 & 92.93 & 0.58 & 26.26 & 14.79 & 1.54 & 0.003232 & 28.40 & 2.01 \\
$14211-2$ & 2.03 & 7.55 & 92.45 & 0.81 & 15.53 & 13.40 & 0.47 & 0.005334 & 17.91 & 1.23 \\
$14211-3$ & 2.00 & 6.54 & 93.46 & 0.83 & 22.01 & 14.04 & 0.71 & 0.004805 & 17.38 & 1.05 \\
$14211-4$ & 2.24 & 9.83 & 90.17 & 0.98 & 19.69 & 14.05 & 0.36 & 0.003372 & 15.68 & 1.01 \\
$14211-5$ & 2.18 & 7.33 & 92.67 & 0.69 & 21.92 & 13.71 & 0.60 & 0.005001 & 16.65 & 1.08 \\
$14221-1$ & 2.30 & 7.13 & 92.87 & 0.65 & 22.76 & 14.41 & 0.46 & 0.003980 & 12.03 & 0.89 \\
$15051-1$ & 2.17 & 6.16 & 93.84 & 0.95 & 11.60 & 12.23 & 0.71 & 0.005120 & 23.69 & 1.17 \\
$15061-1$ & 2.24 & 6.26 & 93.74 & 0.57 & 8.59 & 13.53 & 0.69 & 0.012206 & 21.65 & 0.94 \\
\hline
\end{tabular}

Notes: $R_{o \text { max }}:$ mean maximum vitrinite reflectance; $I_{\mathrm{mmf}}$ : inertinite content; $V_{\mathrm{mmf}}$ : vitrinite content; $M_{\mathrm{ad}}:$ moisture content; $A_{d}:$ ash content; $V_{\mathrm{daf}}:$ volatile matter yield; $S_{\mathrm{BET}}$ : BET specific surface area; $V_{\mathrm{BJH}}$ : BJH pore volume; $V_{L}$ : Langmuir volume (ad); $P_{L}$ : Langmuir pressure (ad); ad: air dry basis; $d$ : dry basis; daf: dry and ash-free basis; mmf: mineral matter-free basis. 


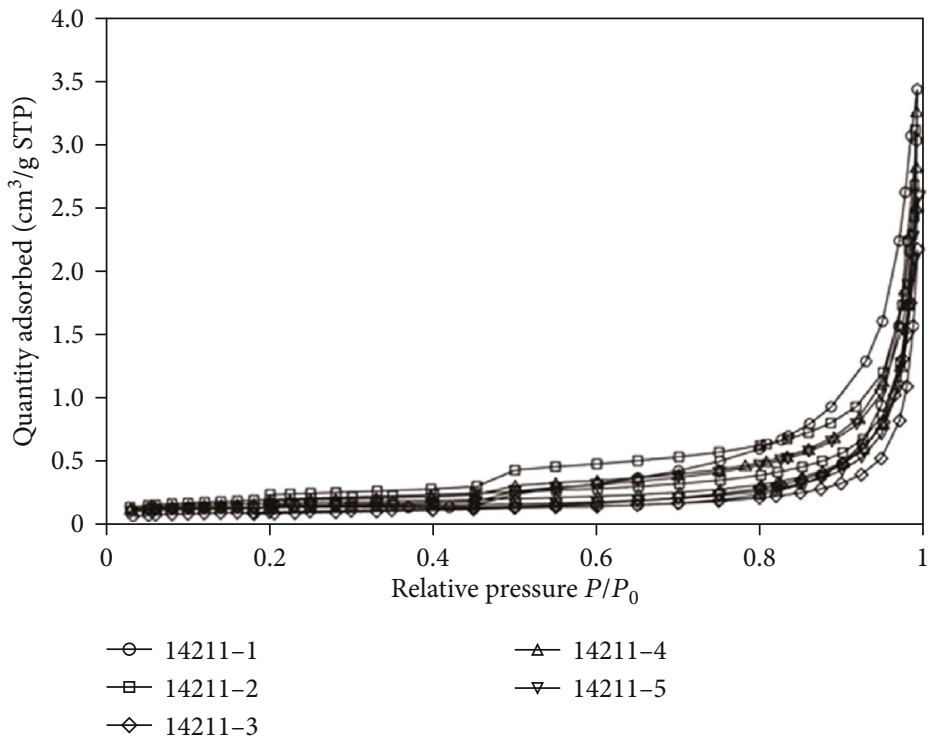

(a)

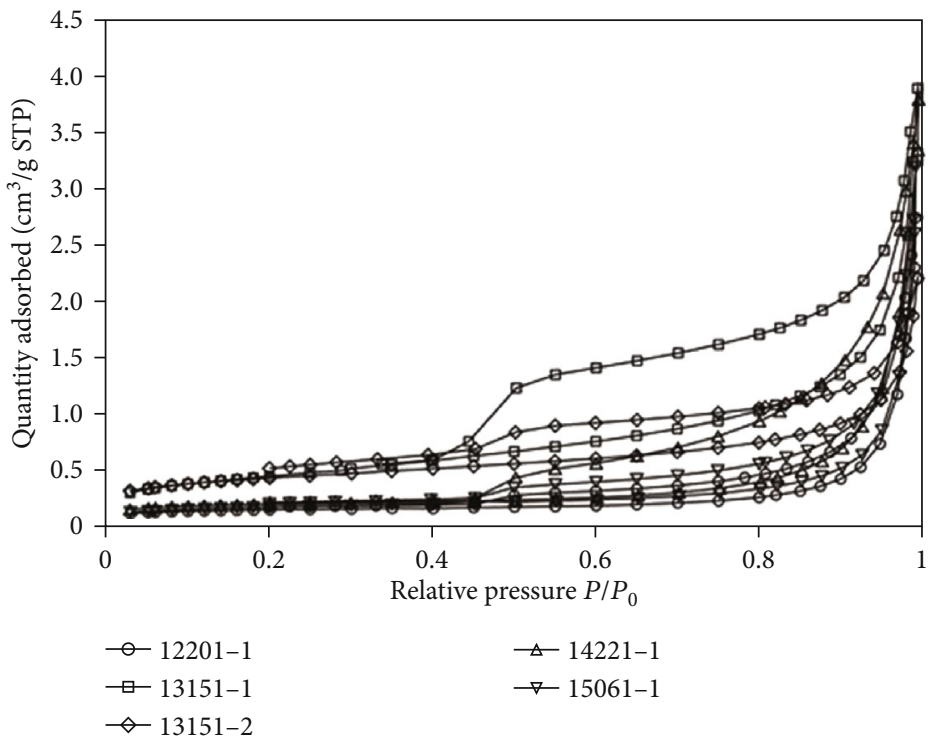

(b)

Figure 2: Continued. 


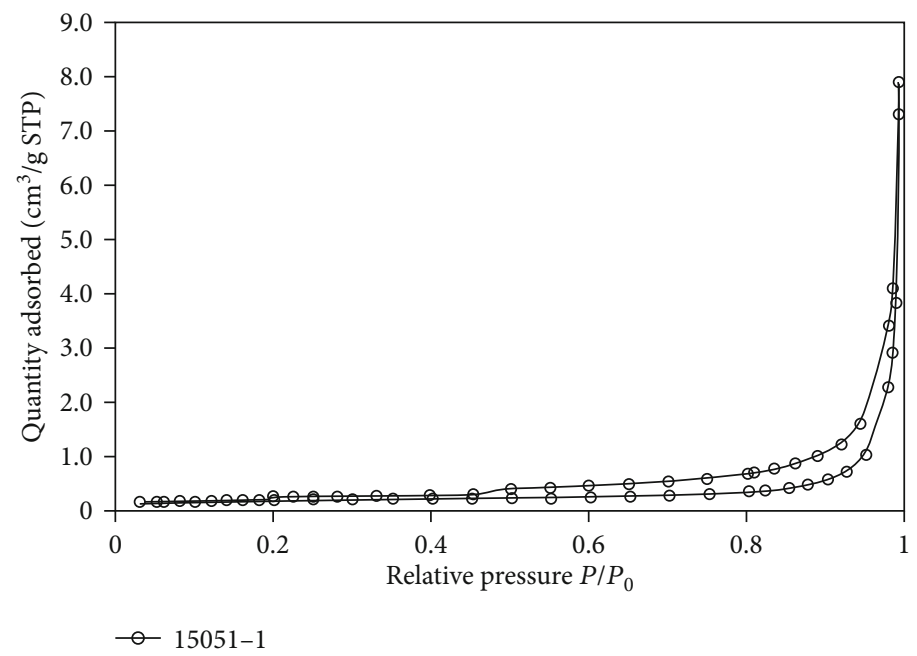

(c)

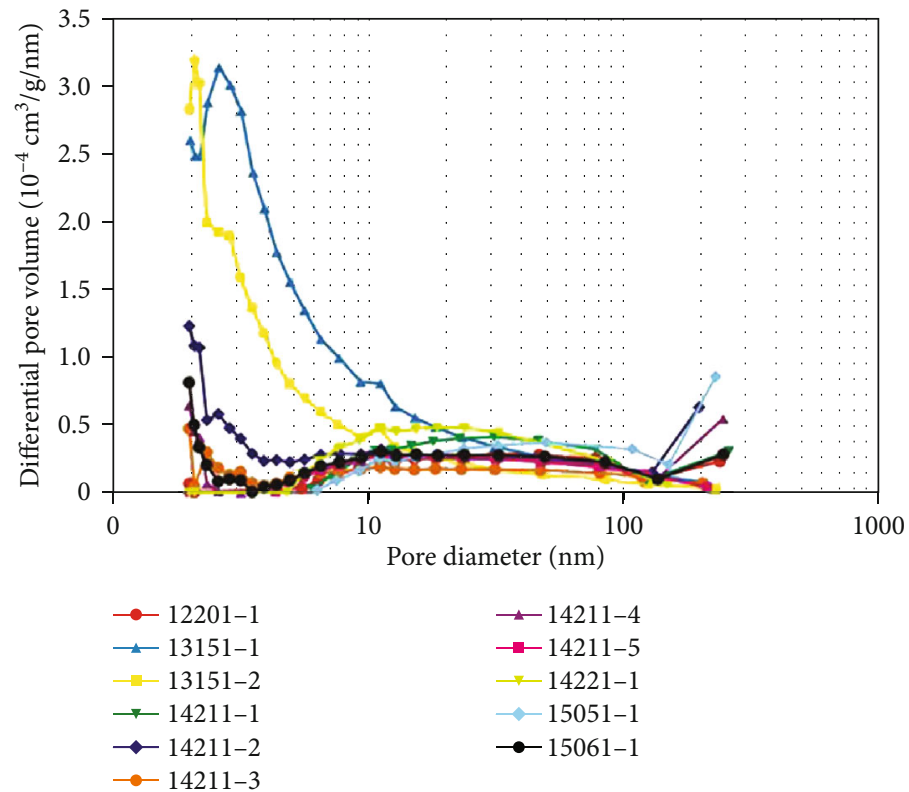

(d)

FIgURE 2: $(\mathrm{a}-\mathrm{c})$ Low-pressure $\mathrm{N}_{2}$ adsorption and desorption isotherms of the No. $2_{1}$ coal samples from different working faces in the Xin'an coal mine. (d) Pore size distributions obtained from adsorption branches of low-pressure $\mathrm{N}_{2}$ adsorption isotherms.

at the relative pressure from 0.45 to 0.995 is considered to be associated with capillary condensation in mesopores [61, 62]. The shape of hysteresis loop is identified with the particular pore structure [63]. The adsorbed nitrogen quantity at the maximum relative pressure varies among coal samples from different working faces, with the maximum value of $7.91 \mathrm{~cm}^{3} / \mathrm{g}$ at the sample $15051-1$ and the minimum value of $2.18 \mathrm{~cm}^{3} / \mathrm{g}$ at the sample $14211-3$. This substantial difference translates into the evident variations in $S_{\mathrm{BET}}, V_{\mathrm{BJH}}$, and PSD. As shown in Table 1, the $S_{\mathrm{BET}}$ and $V_{\mathrm{BJH}}$ of the samples are in the range of $0.36-1.64 \mathrm{~m}^{2} / \mathrm{g}\left(0.76 \mathrm{~m}^{2} / \mathrm{g}\right.$, on average) and $0.0032-0.0122 \mathrm{~cm}^{3} / \mathrm{g}\left(0.0053 \mathrm{~cm}^{3} / \mathrm{g}\right.$, on average $)$, respectively. This is mainly attributed to the heterogeneous pore structure of the coal samples in different locations due to the intense tectonic deformation. The largest $S_{\mathrm{BET}}$ and $V_{\mathrm{BJH}}$ are present in the sample 13151-1 and sample 15051-1, respectively, while the smallest values are in the sample 14211-3 and sample 13151-2, respectively. The PSDs interpreted from the adsorption isotherms are illustrated in Figure 2(d) and can be classified as three types (I, II, and III). Type I (represented by the samples 13151-1 and 13151-2) presents a predominant peak at 2.00-2.60 nm. Type II (represented by the samples 14211-2, 14211-3, 14211-4, 15051-1, and 15061-1) shows the minor peak(s) at the beginning (approximately $2 \mathrm{~nm}$ ) and/or the end (approximately 200-240 nm) of PSD. Type III (represented by the samples 12201-1, 14211-1, 14211-5, and 14221-1) exhibits no peak with respect to PSD. 


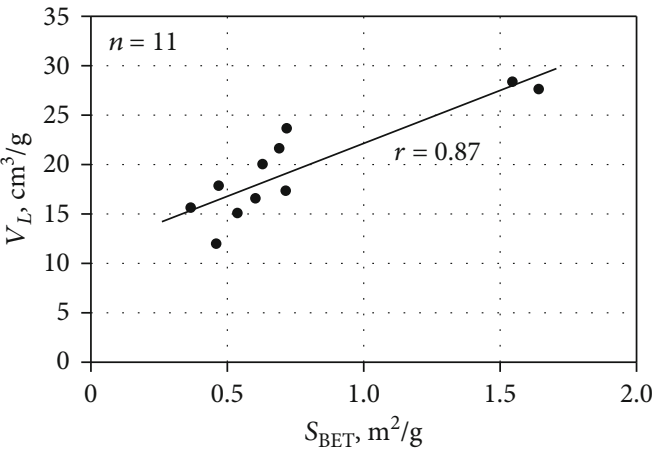

(a)

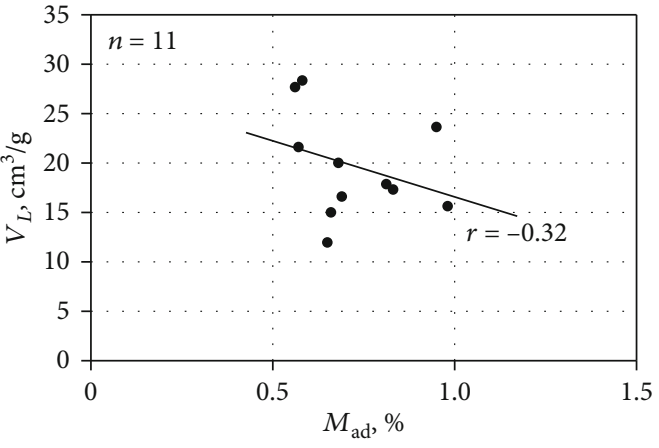

(c)

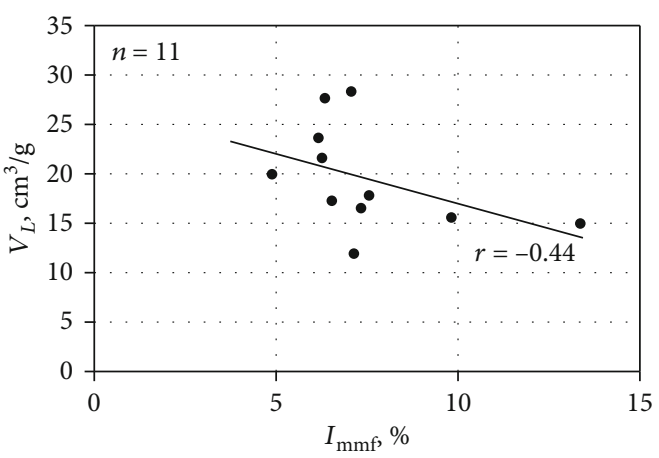

(e)

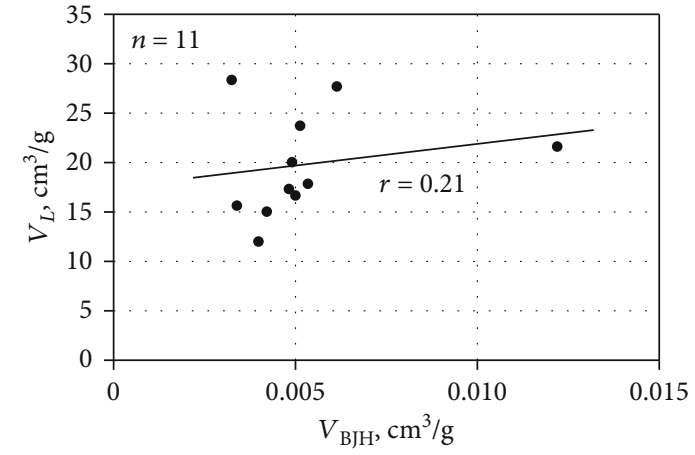

(b)

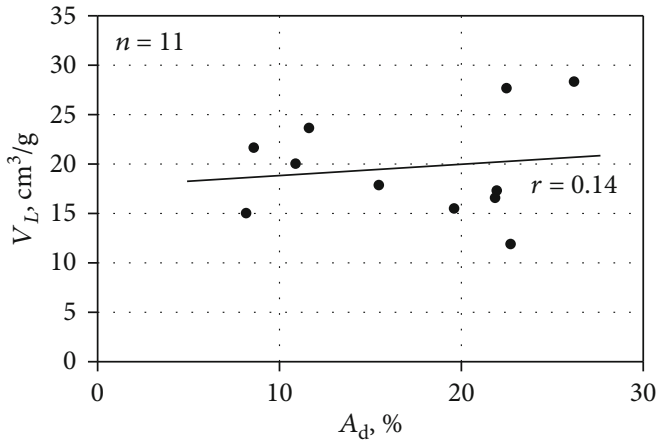

(d)

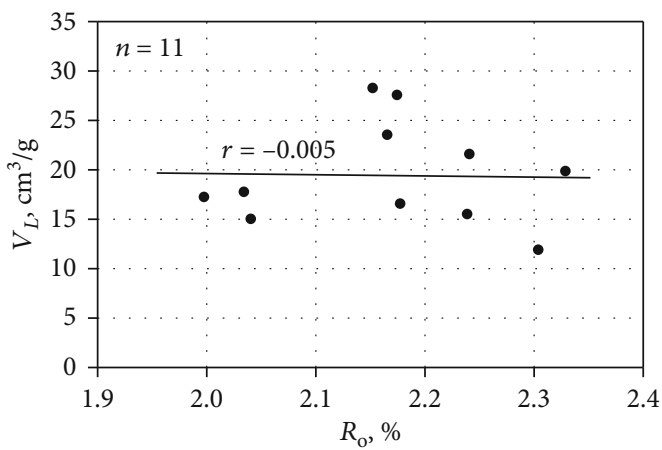

(f)

FIgURE 3: Scatter plots of (a) BET specific surface area, (b) BJH pore volume, (c) moisture content, (d) ash content, (e) inertinite content, and (f) coal rank versus methane adsorption capacity of the No. $2_{1}$ coal in the Xin'an coal mine.

Pore structure parameters including pore specific surface area and pore volume have significant implications on methane adsorption capacity [7, 12, 20, 34, 44, 55, 64], with distinctly different mechanisms (surface adsorption versus pore volume filling) [65]. Moore [12] and Zhou et al. [44] suggested that pore specific surface area is the most important parameter in determining methane adsorption capacity, whereas Clarkson and Bustin [7] concluded that pore volume is more important. It is of great importance to have a better understanding of their roles in methane adsorption capacity in our study. The scatter plot (Figure 3(a)) displays that there is a significant positive correlation between methane adsorption capacity and $S_{\mathrm{BET}}$ with the correlation coefficient of $r=0.87$. This is because gas is predominantly adsorbed on the surface of coal matrix $[4,6,12,43]$. The larger surface area supplies substantial adsorption sites $[24,66]$ and stron- ger adsorbate-adsorbent interaction energy to methane [65] because of the adsorption force on the surface area [5]. This results in the strong positive correlation between methane adsorption capacity and $S_{\mathrm{BET}}$. Compared with $S_{\mathrm{BET}}$, the weak positive correlation between methane adsorption capacity and $V_{\mathrm{BJH}}(r=0.21)$ (Figure $\left.3(\mathrm{~b})\right)$ suggests that the effect of $V_{\mathrm{BJH}}$ on methane adsorption capacity may be covered by that of $S_{\mathrm{BET}}$.

3.2.2. Coal Quality. Coal quality correlates significantly with methane adsorption capacity $[39,40]$. The results of proximate analysis of the samples are listed in Table 1 . The No. 2 coal displays low moisture content (0.56-0.98\%, $0.72 \%$ on average). The scatter plot (Figure 3(c)) shows that methane adsorption capacity has an insignificant negative correlation with moisture content with the $r=-0.32$. Generally, 
methane adsorption capacity decreases with the increasing moisture content until a certain critical moisture content (equilibrium moisture) is reached, after which no influence on methane adsorption capacity is observed $[8,23]$. The presence of moisture weakens the interaction between coal and methane $[17,67]$ and competes with methane for adsorption sites $[13,25,68]$. Because of the polarity of water molecule, moisture is preferentially adsorbed $[69,70]$, which leads to less space available for methane [17]. Once all possible adsorption sites for moisture are occupied, methane adsorption capacity will not decrease any further [23, 70]. Meanwhile, moisture may block the accesses of gas to micropores [13, 71]. As a result, methane adsorption capacity decreases with an increase in moisture content $[8,19,25,31,68,69]$.

Inorganic matter (as indicated by ash content) plays a critical role in methane adsorption capacity $[8,10,19,25$, $44,68,72-74]$. Ash content of studied samples ranges from $8.16 \%$ to $26.26 \%$ (Table 1 ), which is classified as special low ash to medium ash coal according to Chinese National Standard GB/T 15224.1-2010 (Ash yield $<10 \%$ for special low ash coal, $10.01-20 \%$ for low ash coal, and $20.01-30 \%$ for medium ash coal). There is a positive association between ash content and methane adsorption capacity but the relationship lacks statistical significance $(r=0.14)$ (Figure 3(d)). Methane is mainly adsorbed on organic matter rather than mineral matter $[31,56,75]$. Acting as the simple diluent, mineral matter reduces the affinity of methane to the surface of coal matrix [39] and is not likely contribute to methane adsorption sites $[13,21,25]$. The increase in ash content results in the decrease in methane adsorption capacity [7, 19, 35, 56, 69]. However, methane adsorption capacity presents an increasing trend with an increase in ash content in our study. This anomaly suggests that the effect of ash content on methane adsorption capacity may be masked by other influencing factors.

3.2.3. Coal Maceral. As indicated in Table 1, coal maceral is dominated by vitrinite, followed by inertinite, with no occurrence of liptinite. Vitrinite and inertinite range from $86.65 \%$ to $95.10 \%$ and from $4.90 \%$ to $13.35 \%$, averaging at $92.50 \%$ and $7.50 \%$, respectively. Submaceral of vitrinite is mainly telinite and telocollinite, while that of inertinite contains mainly fusinite and some sclerotinite.

The influence of coal maceral on methane adsorption capacity is rank dependent, but with controversies. Laxminarayana and Crosdale [13] indicated that methane adsorption capacity increases with the increasing vitrinite content at high-volatile bituminous coal and decreases at semianthracite and anthracite, whereas methane adsorption capacity is not associated with coal maceral at low-medium-volatile bituminous coal. Liu et al. [26] suggested that methane adsorption capacity of vitrinite is weaker than that of inertinite for low-rank coal, and the opposite is true for highrank coal. Flores [73] concluded that vitrinite-rich coal is characterized by greater methane adsorption capacity than inertinite-rich coal up to low-volatile bituminous coal. In contrast, Ettinger et al. [76] supported the opposite. But they have the consensus that methane adsorption capacity of coal maceral is similar at higher-rank coal (Ettinger et al. [76];
[73]). Chalmers and Bustin [45] suggested that there is no significant difference in methane adsorption capacity of coal maceral for lower-rank coal, but for higher-rank coal, vitrinite-rich coal has higher methane adsorption capacity. For the high-rank coal in our study, the negative correlation $(r=-0.44)$ occurs in inertinite content and methane adsorption capacity (Figure 3(e)), which is in support of the findings of Chalmers and Bustin [45] and Liu et al. [26]. Vitrinite-rich coal is characterized by much more mesopores and micropores than inertinite-rich coal $[7,19,45,64]$ and can provide more adsorption sites for methane [70], which results in the decreasing methane adsorption capacity with an increase of inertinite content.

3.2.4. Coal Rank. As the most important indicator of metamorphism, $R_{o, \max }$ varies from $2.00 \%$ to $2.33 \%$ with the average value of $2.17 \%$ (Table 1 ). The coal is classified as semianthracite, according to the ASTM classification [77]. Coal rank is generally considered to be the dominant parameter affecting methane adsorption capacity $[8,12,13,25,31$, $34,38,45]$. A correlation of second-order polynomial trend ("U" shaped) exists between coal rank and methane adsorption capacity with the minimum value occurring at high- or medium-volatile bituminous coal [10, 13, 19, 39, 46, 71]. Coal rank in our study exceeds medium-volatile bituminous coal, and methane adsorption capacity is supposed to increase with the increasing coal rank. Nevertheless, there is no correlation between coal rank and methane adsorption capacity $(r=-0.005$, Figure 3(f)). The extremely weak negative correlation coefficient suggests that coal rank is not the main factor affecting methane adsorption capacity because of its relatively small variation range.

3.3. Mathematic Model of Methane Adsorption Capacity. Methane adsorption capacity is affected by these various factors, and the contributions of the individual variables to methane adsorption capacity may interact and be likely to be incorrect in univariate analysis. It is necessary to develop a computational scheme of methane adsorption capacity affected by the combined individual variables. Quantification theory I belongs to multivariate statistical analysis method, which can associate quantitative and qualitative variables simultaneously. The CBM geological mathematical model software was developed on the basis of quantification theory I and used to relate methane adsorption capacity to the combined effects of the independent variables in our study. The quantitative variables including $S_{\mathrm{BET}}, V_{\mathrm{BJH}}$, moisture content, ash content, inertinite content, and $R_{o \text {, max }}$ were selected as the independent variables, while methane adsorption capacity as the dependent variable. There are no qualitative variables in the independent variables. The mathematical model containing all analytical factors for methane adsorption capacity established by the software is

$$
\begin{aligned}
y= & 14.3877 \mathrm{~d} 1+211.9483 \mathrm{~d} 2+12.4757 \mathrm{~d} 3-0.2695 \mathrm{~d} 4 \\
& -0.3185 \mathrm{~d} 5+2.6019 \mathrm{~d} 6
\end{aligned}
$$

where $y$ is methane adsorption capacity, $\mathrm{cm}^{3} / \mathrm{g} ; \mathrm{d} 1$ is $S_{\mathrm{BET}}$, 
TABLE 2: Comparison of measured values and calculated values of methane adsorption capacity of the No. $2_{1}$ coal in the Xin'an coal mine.

\begin{tabular}{lcccc}
\hline Coal sample & $\begin{array}{c}\text { Measured value, } V_{M} \\
\mathrm{~cm}^{3} / \mathrm{g}\end{array}$ & $\begin{array}{c}\text { Predicted value, } V_{P} \\
\mathrm{~cm}^{3} / \mathrm{g}\end{array}$ & $\begin{array}{c}\text { Deviation } V_{M}-V_{P} \\
\mathrm{~cm}^{3} / \mathrm{g}\end{array}$ & $\begin{array}{c}\left(\left|V_{M}-V_{P}\right|\right) / V_{M} \\
\%\end{array}$ \\
\hline $12201-1$ & 15.11 & 15.60 & -0.49 & 3.24 \\
$13151-1$ & 27.69 & 29.44 & -1.75 & 6.32 \\
$13151-2$ & 28.40 & 26.34 & 2.06 & 7.25 \\
$14211-1$ & 17.91 & 16.69 & 1.22 & 6.81 \\
$14211-2$ & 17.38 & 18.78 & -1.40 & 8.06 \\
$14211-3$ & 15.68 & 15.51 & 0.17 & 1.08 \\
$14211-4$ & 16.65 & 15.73 & 0.92 & 5.53 \\
$14211-5$ & 12.03 & 13.15 & -1.12 & 9.31 \\
$14221-1$ & 23.69 & 23.71 & -0.02 & 0.08 \\
$15051-1$ & 21.65 & 21.15 & 0.50 & 2.31 \\
$15061-1$ & 20.07 & 20.16 & -0.09 & 0.45 \\
\hline
\end{tabular}

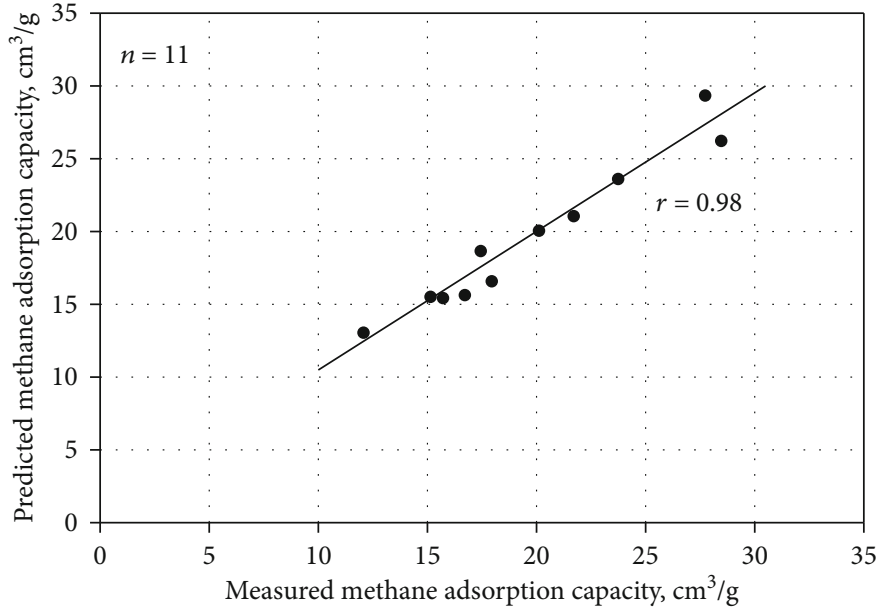

Figure 4: Scatter plot of measured versus predicted methane adsorption capacity of the No. $2_{1}$ coal in the Xin'an coal mine.

$\mathrm{m}^{2} / \mathrm{g} ; \mathrm{d} 2$ is $V_{\mathrm{BJH}}, \mathrm{cm}^{3} / \mathrm{g} ; \mathrm{d} 3$ is moisture content, \%; $\mathrm{d} 4$ is ash content, \%; $\mathrm{d} 5$ is inertinite content, \%; $\mathrm{d} 6$ is $R_{o, \max }, \%$.

The model was checked using ANOVA (i.e., analysis of variance, $F$-test) method [78]. The $F$-distribution for $F$-test of the mathematical model is 12.98 , which is larger than the $F_{0.1}=4.01$ (the value of the $F$-distribution at the $10 \%$ significance level). The F-test suggests that the mathematical model is proved to be significant. Consequently, the mathematical model can be used to evaluate methane adsorption capacity of the No. $2_{1}$ coal in our study area.

The measured values from the experiment and the predicted values from the mathematical model of methane adsorption capacity are listed in Table 2. The deviation of the measured values to the predicted values varies from $-1.75 \mathrm{~cm}^{3} / \mathrm{g}$ to $2.06 \mathrm{~cm}^{3} / \mathrm{g}$. The maximum and minimum deviations are belonging to the working face 13151, which is mainly attributed to the relatively high methane adsorption capacity. The relative error varies from $0.08 \%$ to $9.31 \%$ with the average value of $4.59 \%$. The correlation coefficient between the measured values and the predicted values of methane adsorption capacity is 0.98 , as illustrated in
Figure 4, indicating there is a good consistency between the mathematical model prediction and the experimental measurement.

3.4. Comparison of Univariate Analysis and Multivariate Analysis. For the univariate analysis expressed by the scatter plots, the correlation coefficients suggest that the contributions of the analytical factors to methane adsorption capacity in a descending order are as follows: $S_{\mathrm{BET}}$, inertinite content, moisture content, $V_{\mathrm{BJH}}$, ash content, and $R_{o \text {,max }}$. Methane adsorption capacity is positively correlated with $S_{\mathrm{BET}}, V_{\mathrm{BJH}}$, and ash content, is negatively correlated with inertinite content and moisture content, and has no correlation with $R_{o \text {, max }}$ . For the multivariate analysis expressed by the mathematical model, the partial correlation coefficients of independent variables are, in same order as the mathematical model, 0.96, $0.28,0.74,0.73,0.43$, and 0.18 , respectively. This implies that the contributions of independent variables to methane adsorption capacity from large to small are $S_{\mathrm{BET}}$, moisture content, ash content, inertinite content, $V_{\mathrm{BJH}}$, and $R_{o \text {, max }}$. Methane adsorption capacity has positive relationships with 
$S_{\mathrm{BET}}, V_{\mathrm{BJH}}$, moisture content, and $R_{o \text {, max }}$ and negative relationships with ash content and inertinite content according to the mathematical model.

There are similarities and differences between the univariate analysis and the multivariate analysis. The similarities are that $S_{\mathrm{BET}}$ has the greatest contribution to methane adsorption capacity, while $R_{o \text {, max }}$ has the least contribution. The differences are reflected in two aspects. Firstly, the contributions of the other influencing factors $\left(S_{\mathrm{BET}}\right.$ and $R_{o \text {, max }}$ not included) are in different orders. Taking inertinite content as an example, it ranks second in the univariate analysis but fourth in the multivariate analysis. Secondly, the positive or negative relationships of some influencing factors such as ash content present the opposite in the two analyses. Because the mathematic model synthetically covers the combined effects of the influencing factors, it is more representative in evaluating methane adsorption capacity.

\section{Conclusions}

Methane adsorption isotherm experiments on semianthracite collected from the Xin'an coal mine, Henan Province, China, were conducted to investigate the effects of pore structure, coal quality, coal maceral, and coal rank on methane adsorption capacity using univariate analysis expressed by the scatter plots and multivariate analysis expressed by the mathematical model. The key conclusions are summarized as follows:

(1) Methane adsorption capacity varies widely from $12.03 \mathrm{~cm}^{3} / \mathrm{g}$ to $28.40 \mathrm{~cm}^{3} / \mathrm{g}$, suggesting a remarkable difference for the coal with similar rank $(2.00-2.33 \%$ $\left.R_{o, \max }\right)$

(2) In univariate analysis, methane adsorption capacity has a strong positive correlation with $S_{\mathrm{BET}}(r=0.87)$, weak positive correlations with $V_{\mathrm{BJH}}(r=0.21)$ and ash content $(r=0.14)$, weak negative correlations with moisture content $(r=-0.32)$ and inertinite content $(r=-0.44)$, and no correlation with $R_{o \text {, max }}$ $(r=-0.005)$

(3) In multivariate analysis, the mathematical model of methane adsorption capacity is established:

$$
\begin{aligned}
y= & 14.3877 \mathrm{~d} 1+211.9483 \mathrm{~d} 2+12.4757 \mathrm{~d} 3-0.2695 \mathrm{~d} 4 \\
& -0.3185 \mathrm{~d} 5+2.6019 \mathrm{~d} 6,
\end{aligned}
$$

where $y$ is methane adsorption capacity; $\mathrm{d} 1$ to $\mathrm{d} 6$ represent $S_{\mathrm{BET}}, V_{\mathrm{BJH}}$, moisture content, ash content, inertinite content, and $R_{o \text {, } \max }$, respectively

(4) $\mathrm{S}_{\mathrm{BET}}$ has the greatest contribution to methane adsorption capacity, while $R_{o \text {, max }}$ has the least contribution in both univariate analysis and multivariate analysis. The differences in the two analyses are that the other influencing factors contribute differently to methane adsorption capacity, and the positive or negative correlations of some influencing factors present the opposite

(5) The mathematic model is more representative in evaluating methane adsorption capacity because it covers the combined effects of the influencing factors

\section{Data Availability}

All data generated or analyzed during this study are included in this article.

\section{Conflicts of Interest}

The authors declare that there is no conflict of interest.

\section{Acknowledgments}

We gratefully acknowledge the financial support from the National Natural Science Foundation of China (grant numbers 41972184 and 41902177) and the research foundation of Jiangxi Provincial Department of Education of China (grant number GJJ190570). We sincerely appreciate the anonymous reviewers and the associate editor for their constructive comments to substantially improve the manuscript.

\section{References}

[1] A. D. Alexeev, E. V. Ulyanova, G. P. Starikov, and N. N. Kovriga, "Latent methane in fossil coals," Fuel, vol. 83, no. 10, pp. 14071411, 2004.

[2] W. D. Gunter, T. Gentzis, B. A. Rottenfusser, and R. J. H. Richardson, "Deep coalbed methane in Alberta, Canada: a fuel resource with the potential of zero greenhouse gas emissions," Energy Conversion and Management, vol. 38, pp. S217-S222, 1997.

[3] K. Noak, "Control of gas emissions in underground coal mines," International Journal of Coal Geology, vol. 35, no. 1-4, pp. 57-82, 1998.

[4] D. D. Rice, "Composition and origins of coalbed gas," in Hydrocarbons from Coal, B. E. Law and D. D. Rice, Eds., pp. 159-184, AAPG Studies in Geology, 1993.

[5] C. T. Rightmire, "Coalbed methane resource," in Coalbed Methane Resources of the United States, C. T. Rightmire, G. E. Eddy, and J. N. Kirr, Eds., pp. 1-13, AAPG Studies in Geology, 1984.

[6] A. Busch and Y. Gensterblum, "CBM and $\mathrm{CO}_{2}$-ECBM related sorption processes in coal: a review," International Journal of Coal Geology, vol. 87, no. 2, pp. 49-71, 2011.

[7] C. R. Clarkson and R. M. Bustin, "Variation in micropore capacity and size distribution with composition in bituminous coal of the Western Canadian Sedimentary Basin: implications for coalbed methane potential," Fuel, vol. 75, no. 13, pp. 1483 $1498,1996$.

[8] A. Hildenbrand, B. M. Krooss, A. Busch, and R. Gaschnitz, "Evolution of methane sorption capacity of coal seams as a function of burial history-a case study from the Campine Basin, NE Belgium," International Journal of Coal Geology, vol. 66, no. 3, pp. 179-203, 2006.

[9] C. Ö. Karacan and E. Okandan, "Assessment of energetic heterogeneity of coals for gas adsorption and its effect on mixture 
predictions for coalbed methane studies," Fuel, vol. 79, no. 15, pp. 1963-1974, 2000.

[10] J. R. Levine, "Coalification: the evolution of coal as source rock and reservoir," in Hydrocarbons from Coal, B. E. Law and D. D. Rice, Eds., pp. 39-77, AAPG Studies in Geology, 1993.

[11] J. Milewska-Duda, J. Duda, A. Nodzeñski, and J. Lakatos, "Absorption and adsorption of methane and carbon dioxide in hard coal and active carbon," Langmuir, vol. 16, no. 12, pp. 5458-5466, 2000.

[12] T. A. Moore, "Coalbed methane: a review," International Journal of Coal Geology, vol. 101, pp. 36-81, 2012.

[13] C. Laxminarayana and P. J. Crosdale, "Role of coal type and rank on methane sorption characteristics of Bowen Basin, Australia coals," International Journal of Coal Geology, vol. 40, no. 4, pp. 309-325, 1999.

[14] S. Hao, J. Wen, X. Yu, and W. Chu, "Effect of the surface oxygen groups on methane adsorption on coals," Applied Surface Science, vol. 264, pp. 433-442, 2013.

[15] Q. Zhang, "Development and current situation of study on theory of methane adsorption on coal," Procedia Earth and Planetary Science, vol. 3, pp. 318-324, 2011.

[16] M. Heuchel, G. M. Davies, E. Buss, and N. A. Seaton, “Adsorption of carbon dioxide and methane and their mixtures on an activated carbon: simulation and experiment," Langmuir, vol. 15, no. 25, pp. 8695-8705, 1999.

[17] J. Zhang, M. B. Clennell, D. N. Dewhurst, and K. Liu, "Combined Monte Carlo and molecular dynamics simulation of methane adsorption on dry and moist coal," Fuel, vol. 122, pp. 186-197, 2014.

[18] S. Zhang and S. Sang, "Physical chemistry mechanism of influence of liquid water on coalbed methane adsorption," Procedia Earth and Planetary Science, vol. 1, no. 1, pp. 263-268, 2009.

[19] R. M. Bustin and C. R. Clarkson, "Geological controls on coalbed methane reservoir capacity and gas content," International Journal of Coal Geology, vol. 38, no. 1-2, pp. 3-26, 1998.

[20] C. R. Clarkson and R. M. Bustin, "The effect of pore structure and gas pressure upon the transport properties of coal: a laboratory and modeling study. 1 . Isotherms and pore volume distributions," Fuel, vol. 78, no. 11, pp. 1333-1344, 1999.

[21] P. J. Crosdale, B. B. Beamish, and M. Valix, "Coalbed methane sorption related to coal composition," International Journal of Coal Geology, vol. 35, no. 1-4, pp. 147-158, 1998.

[22] C. Guan, S. Liu, C. Li, Y. Wang, and Y. Zhao, "The temperature effect on the methane and $\mathrm{CO}_{2}$ adsorption capacities of Illinois coal," Fuel, vol. 211, pp. 241-250, 2018.

[23] B. M. Krooss, F. van Bergen, Y. Gensterblum, N. Siemons, H. J. M. Pagnier, and P. David, "High-pressure methane and carbon dioxide adsorption on dry and moisture-equilibrated Pennsylvanian coals," International Journal of Coal Geology, vol. 51, no. 2, pp. 69-92, 2002.

[24] M. N. Lamberson and R. M. Bustin, "Coalbed methane characteristics of Gates Formation coals, northeastern British Columbia: effect of maceral composition," AAPG Bulletin, vol. 77, pp. 2062-2076, 1993.

[25] C. Laxminarayana and P. J. Crosdale, "Controls on methane sorption capacity of Indian coals," AAPG Bulletin, vol. 86, pp. 201-212, 2002.

[26] L. Liu, C. Jin, L. Li et al., "Coalbed methane adsorption capacity related to maceral compositions," Energy Exploration \& Exploitation, vol. 38, no. 1, pp. 79-91, 2020.
[27] Y. Liu, Y. Zhu, S. Liu, W. Li, and X. Tang, "Temperature effect on gas adsorption capacity in different sized pores of coal: experiment and numerical modeling," Journal of Petroleum Science and Engineering, vol. 165, pp. 821-830, 2018.

[28] K. Mosher, J. He, Y. Liu, E. Rupp, and J. Wilcox, "Molecular simulation of methane adsorption in micro- and mesoporous carbons with applications to coal and gas shale systems," International Journal of Coal Geology, vol. 109-110, pp. 36-44, 2013.

[29] J. Pan, Q. Hou, Y. Ju, H. Bai, and Y. Zhao, "Coalbed methane sorption related to coal deformation structures at different temperatures and pressures," Fuel, vol. 102, pp. 760-765, 2012.

[30] A. Saghafi, K. L. Pinetown, P. G. Grobler, and J. H. P. van Heerden, " $\mathrm{CO}_{2}$ storage potential of South African coals and gas entrapment enhancement due to igneous intrusions," International Journal of Coal Geology, vol. 73, pp. 74-87, 2008.

[31] A. R. Scott, "Hydrogeologic factors affecting gas content distribution in coal beds," International Journal of Coal Geology, vol. 50, no. 1-4, pp. 363-387, 2002.

[32] F. Wang, Y. Yao, Z. Wen, Q. Sun, and X. Yuan, "Effect of water occurrences on methane adsorption capacity of coal: a comparison between bituminous coal and anthracite coal," Fuel, vol. 266, p. 117102, 2020.

[33] Z. Wang, W. Su, X. Tang, and J. Wu, "Influence of water invasion on methane adsorption behavior in coal," International Journal of Coal Geology, vol. 197, pp. 74-83, 2018.

[34] Y. Yao, D. Liu, D. Tang, S. Tang, Y. Che, and W. Huang, "Preliminary evaluation of the coalbed methane production potential and its geological controls in the Weibei Coalfield, Southeastern Ordos Basin, China," International Journal of Coal Geology, vol. 78, no. 1, pp. 1-15, 2009.

[35] L. Zhang, D. Yan, S. Yang et al., "Effects of sequence stratigraphy on coal characteristics and $\mathrm{CH}_{4}$ adsorption capacity of the low-rank coal in Santanghu Basin, China," Journal of Natural Gas Science and Engineering, vol. 81, p. 103467, 2020.

[36] C. Zhu, J. Ren, J. Wan, B. Q. Lin, K. Yang, and Y. Li, “Methane adsorption on coals with different coal rank under elevated temperature and pressure," Fuel, vol. 254, p. 115686, 2019.

[37] X. Liu, D. Song, X. He et al., "Coal macromolecular structural characteristic and its influence on coalbed methane adsorption," Fuel, vol. 222, pp. 687-694, 2018.

[38] J. Meng, S. Li, and J. Niu, "Crystallite structure characteristics and its influence on methane adsorption for different rank coals," ACS Omega, vol. 4, no. 24, pp. 20762-20772, 2019.

[39] Q. Li, B. Lin, K. Wang, M. Zhao, and M. Ruan, "Surface properties of pulverized coal and its effects on coal mine methane adsorption behaviors under ambient conditions," Powder Technology, vol. 270, pp. 278-286, 2015.

[40] P. Dutta, S. Bhowmik, and S. Das, "Methane and carbon dioxide sorption on a set of coals from India," International Journal of Coal Geology, vol. 85, no. 3-4, pp. 289-299, 2011.

[41] H. Liu, J. Mou, and Y. Cheng, "Impact of pore structure on gas adsorption and diffusion dynamics for long-flame coal," Journal of Natural Gas Science and Engineering, vol. 22, pp. 203213, 2015.

[42] J. Zhao, H. Xu, D. Tang, J. P. Mathews, S. Li, and S. Tao, "Coal seam porosity and fracture heterogeneity of macrolithotypes in the Hancheng Block, eastern margin, Ordos Basin, China," International Journal of Coal Geology, vol. 159, pp. 18-29, 2016.

[43] Y. Zhao, C. Jiang, and W. Chu, "Methane adsorption behavior on coal having different pore structures," International Journal 
of Mining Science and Technology, vol. 22, no. 6, pp. 757-761, 2012.

[44] S. Zhou, D. Liu, Y. Cai, Z. Karpyn, and Y. Yao, "Comparative analysis of nanopore structure and its effect on methane adsorption capacity of Southern Junggar coalfield coals by gas adsorption and FIB-SEM tomography," Microporous and Mesoporous Materials, vol. 272, pp. 117-128, 2018.

[45] G. R. L. Chalmers and R. M. Bustin, "On the effects of petrographic composition on coalbed methane sorption," International Journal of Coal Geology, vol. 69, no. 4, pp. 288-304, 2007.

[46] D. Yee, J. P. Seidle, and W. B. Hanson, "Gas sorption on coal and measurement of gas content," in Hydrocarbons from Coal, B. E. Law and D. D. Rice, Eds., pp. 203-218, AAPG Studies in Geology, 1993.

[47] ASTM Standard D3173-11, Test method for moisture in the analysis sample of coal and coke, ASTM International, West Conshohocken, PA, 2011.

[48] ASTM Standard D3175-11, Test method for volatile matter in the analysis sample of coal and coke, ASTM International, West Conshohocken, PA, 2011.

[49] ASTM Standard D3174-11, Test method for ash in the analysis sample of coal and coke, ASTM International, West Conshohocken, PA, 2011.

[50] S. M. Mardon, C. F. Eble, J. C. Hower, K. Takacs, M. Mastalerz, and R. Marc Bustin, "Organic petrology, geochemistry, gas content and gas composition of Middle Pennsylvanian age coal beds in the Eastern Interior (Illinois) Basin: implications for CBM development and carbon sequestration," International Journal of Coal Geology, vol. 127, pp. 56-74, 2014.

[51] S. Brunauer, P. H. Emmett, and E. Teller, "Adsorption of gases in multimolecular layers," Journal of the American Chemical Society, vol. 60, no. 2, pp. 309-319, 1938.

[52] E. P. Barrett, L. G. Joyner, and P. P. Halenda, "The determination of pore volume and area distributions in porous substances. I. computations from nitrogen isotherms," Journal of the American Chemical Society, vol. 73, no. 1, pp. 373-380, 1951.

[53] GB/T 19560-2008, "Chinese National Standard," Coal, Experimental method of high-pressure adsorption isothermal to coalcapacity method, National Standardization Management Committee, 2008.

[54] I. Langmuir, "The adsorption of gases on plane surfaces of glass, mica and platinum," Journal of the American Chemical Society, vol. 40, no. 9, pp. 1361-1403, 1918.

[55] Q. Zou, B. Lin, T. Liu, Y. Zhou, Z. Zhang, and F. Z. Yan, "Variation of methane adsorption property of coal after the treatment of hydraulic slotting and methane pre-drainage: a case study," Journal of Natural Gas Science and Engineering, vol. 20, pp. 396-406, 2014.

[56] T. A. Moore, M. Bowe, and C. Nas, "High heat flow effects on a coalbed methane reservoir, East Kalimantan (Borneo), Indonesia," International Journal of Coal Geology, vol. 131, pp. 7-31, 2014.

[57] H. Xu, D. Z. Tang, D. M. Liu et al., "Study on coalbed methane accumulation characteristics and favorable areas in the Binchang area, southwestern Ordos Basin, China," International Journal of Coal Geology, vol. 95, pp. 1-11, 2012.

[58] S. Li, D. Tang, H. Xu, and Z. Yang, "The pore-fracture system properties of coalbed methane reservoirs in the Panguan Syncline, Guizhou, China," Geoscience Frontiers, vol. 3, no. 6, pp. 853-862, 2012.
[59] Y. Meng, D. Tang, H. Xu, C. Li, L. Li, and S. Meng, "Geological controls and coalbed methane production potential evaluation: a case study in Liulin area, eastern Ordos Basin, China," Journal of Natural Gas Science and Engineering, vol. 21, pp. 95-111, 2014.

[60] S. J. Gregg and K. S. W. Sing, Adsorption, Surface Area and Porosity, Academic Press, New York, 2nd edition, 1982.

[61] K. S. W. Sing, D. H. Everett, R. A. W. Haul et al., "Reporting physisorption data for gas/solid systems with special reference to the determination of surface area and porosity (Recommendations 1984)," Pure and Applied Chemistry, vol. 57, no. 4, pp. 603-619, 1985.

[62] F. Rouquerol, J. Rouquerol, K. S. W. Sing, G. Maurin, and P. Llewellyn, "Introduction," in Adsorption by Powders and Porous Solids: Principles, Methodology and Applications, J. Rouquerol, F. Rouquerol, K. S. W. Sing, P. Llewellyn, and G. Maurin, Eds., pp. 1-24, Elsevier, Amsterdam, 2nd edition, 2012.

[63] Y.-D. Cai, D.-M. Liu, Z.-H. Liu, Y.-F. Zhou, and Y. Che, "Evolution of pore structure, submaceral composition and produced gases of two Chinese coals during thermal treatment," Fuel Processing Technology, vol. 156, pp. 298-309, 2017.

[64] M. Mastalerz, A. Drobniak, D. Strąpoć, W. Solano Acosta, and J. Rupp, "Variations in pore characteristics in high volatile bituminous coals: implications for coal bed gas content," International Journal of Coal Geology, vol. 76, no. 3, pp. 205-216, 2008.

[65] R. Heller and M. Zoback, "Adsorption of methane and carbon dioxide on gas shale and pure mineral samples," Journal of Unconventional Oil and Gas Resources, vol. 8, pp. 14-24, 2014.

[66] H. Gan, S. P. Nandi, and P. L. Walker Jr., "Nature of the porosity in American coals," Fuel, vol. 51, no. 4, pp. 272-277, 1972.

[67] H. Kumar, D. Elsworth, J. Liu, D. Pone, and J. P. Mathews, "Optimizing enhanced coalbed methane recovery for unhindered production and $\mathrm{CO}_{2}$ injectivity," International Journal of Greenhouse Gas Control, vol. 11, pp. 86-97, 2012.

[68] P. J. Crosdale, T. A. Moore, and T. E. Mares, "Influence of moisture content and temperature on methane adsorption isotherm analysis for coals from a low-rank, biogenically-sourced gas reservoir," International Journal of Coal Geology, vol. 76, no. 1-2, pp. 166-174, 2008.

[69] C. R. Clarkson and R. M. Bustin, "Binary gas adsorption/desorption isotherms: effect of moisture and coal composition upon carbon dioxide selectivity over methane," International Journal of Coal Geology, vol. 42, no. 4, pp. 241-271, 2000.

[70] G. G. X. Wang, X. Zhang, X. Wei, X. Fu, B. Jiang, and Y. Qin, "A review on transport of coal seam gas and its impact on coalbed methane recovery," Frontiers of Chemical Science and Engineering, vol. 5, no. 2, pp. 139-161, 2011.

[71] D. Prinz and R. Littke, "Development of the micro- and ultramicroporous structure of coals with rank as deduced from the accessibility to water," Fuel, vol. 84, pp. 1645-1652, 2005.

[72] S. Day, R. Fry, and R. Sakurovs, "Swelling of coal in carbon dioxide, methane and their mixtures," International Journal of Coal Geology, vol. 93, pp. 40-48, 2012.

[73] R. M. Flores, "Coalbed methane: from hazard to resource," International Journal of Coal Geology, vol. 35, no. 1-4, pp. 3-26, 1998.

[74] Y. Gensterblum, A. Busch, and B. M. Krooss, "Molecular concept and experimental evidence of competitive adsorption of $\mathrm{H}_{2} \mathrm{O}, \mathrm{CO}_{2}$ and $\mathrm{CH}_{4}$ on organic material," Fuel, vol. 115, pp. 581-588, 2014. 
[75] C. I. Butland and T. A. Moore, "Secondary biogenic coal seam gas reservoirs in New Zealand: a preliminary assessment of gas contents," International Journal of Coal Geology, vol. 76, no. 1-2, pp. 151-165, 2008.

[76] I. Ettinger, I. Eremin, B. Zimakov, and M. Yanovska, "Natural factors influencing coal sorption properties. I. Petrography and sorption properties of coals," Fuel, vol. 45, pp. 267-275, 1966.

[77] ASTM Standard D388-15, Classification of coals by rank, ASTM International, West Conshohocken, PA, 2015.

[78] M. L. Patten, Understanding Research Methods: An Overview of the Essentials, Pyrczak Publishing, Los Angeles, 3rd edition, 2002. 